\title{
Effects of topical $0.8 \%$ piroxicam and $50+$ sunscreen filters on actinic keratosis in hypertensive patients treated with or without photosensitizing diuretic drugs: an observational cohort study
}

This article was published in the following Dove Press journal:

Clinical, Cosmetic and Investigational Dermatology

\section{Sara Mazzilli' \\ Virginia Garofalo' \\ Alessandra Ventura' \\ Laura Diluvio' \\ Massimo Milani ${ }^{2}$ \\ Luca Bianchi' \\ Elena Campione'}

'Department of Dermatology, University of Rome "Tor Vergata", Rome, Italy; ${ }^{2}$ Medical Department, Cantabria Labs Difa Cooper, Caronno Pertusella, Italy
Correspondence: Massimo Milani Cantabria Labs Difa Cooper, Via Milano 160, Caronno Pertusella (VA), 21042, Italy

Tel +3902965 9031

Email massimo.milani@difacooper.com
Background: Photosensitizing diuretics use (especially thiazide compounds) is associated with a significantly higher risk of squamous cell carcinoma (SCC). Actinic keratosis (AK) is a precursor of SCC.

Study aim: To evaluate in a prospective cohort study the efficacy of topical piroxicam $0.8 \%$ and sunscreen $50+(\mathrm{ACTX})$ in the treatment of $\mathrm{AK}$ in hypertensive subjects with or without TD treatment.

Subjects and methods: A total of 119 hypertensive subjects with multiple AK (39 under chronic TD treatment; and 80 treated with other non-TD, non-photosensitizing antihypertensive drugs) were enrolled after their informed consent in a 6-month observational cohort study. All the subjects were treated with ACTX twice daily. The primary endpoint was the evolution of AK lesions at baseline, after 3 and 6 months. The secondary endpoint was the clearance of AK target lesions and field of cancerization by dermoscopic evaluation using a score evaluating erythema, scaling, pigmentation, and follicular plugs (ESPFP score; ranging from 0 to 20). An investigator, unaware of the type of antihypertensive treatments (TD or non-TD), performed all the clinical and dermoscopy evaluations.

Results: At baseline, AK mean (SD) lesion number in TD group was 14.1(4) and 14.6(4) in the non-TD group. ESPFP mean (SD) score at baseline was 5.8(1.2) in both groups. A significant reduction of AK lesions in comparison with baseline was observed in both groups. A statistically significant greater reduction was observed in TD in comparison with the non-TD group $(-54 \%$ vs $-32 \%)$. ESPFP score was reduced in a higher proportion in the TD group in comparison with the non-TD group ( $-60 \%$ vs $-37 \%$, respectively). ACTX treatment was very well tolerated.

Conclusion: In hypertensive subjects with multiple AK, the topical use of ACTX is associated with a significant reduction of lesions count with an improvement in the field cancerization. The clinical efficacy is more pronounced in subjects under thiazide diuretics treatment.

Keywords: actinic keratosis, piroxicam, thiazide diuretics, skin cancer

\section{Introduction}

Actinic keratosis (AK) are cutaneous pre-cancer skin lesions commonly diagnosed in older adults. ${ }^{1}$ They result from the abnormal proliferation of atypical keratinocytes. AK is now considered as a precursor of squamous cell carcinoma (SCC) even if the rate of progression is difficult to establish. ${ }^{2} \mathrm{AK}$ prevalence is variable. ${ }^{3} \mathrm{AK}$ are more common among men than women and increases steadily with age and lifetime hours spent in the sun. ${ }^{4} \mathrm{AK}$ risk factors included male gender, advanced age, sun-sensitive skin, 
prolonged immunosuppression, high level of sun exposure and drug medication intake. ${ }^{5}$ The increase in life expectancy influences lifestyle habits and increase the prevalence of chronic diseases such as hypertension which in turn results in drugs chronic intake. There is evidence that photosensitivity induced by drugs followed by sun exposure may enhance the risk of sunburns and photo-damage, increasing skin cancers risk. ${ }^{6,7}$ The photosensitizing properties of medications are due to their chemical structures that promote the absorption of ultraviolet radiation (UVR). ${ }^{8}$ Drugs containing chlorine substituents in their chemical composition, such as hydrochlorothiazide, furosemide, and chlorpromazine, can cause UV-mediated acute DNA damage through free radical formation. ${ }^{9}$ Furthermore, many diuretics (loop diuretics, furosemide, sodium sparing diuretics like spironolactone and amiloride, and thiazides) are photosensitizing. ${ }^{10} \mathrm{~A}$ multicenter controlled study reported a correlation between thiazide drugs intake and an increase of AK and SCC. ${ }^{11}$ The intake of thiazide diuretic (TD) increases the risk of AK development with an OR of 3.18. ${ }^{12}$ Interestingly, diuretics use is associated with a high risk of sunburns. ${ }^{13}$ Skin cancer risk associated with TD intake could be related to an increase of prostaglandins (PG) production. For this reason, we decided to assess in a cohort study the clinical efficacy of topical piroxicam (PXM) $0.8 \%$, an inhibitor of $\mathrm{PG}$ production, and sunscreens $50 \mathrm{SPF}+$ in the treatment of AK in hypertensive patients treated with and without photosensitizing diuretics and if its clinical efficacy in terms of AK absolute reduction is correlated or not with the type of antihypertensive regimen.

\section{Study design}

We performed an observational cohort study from March 2016 to December 2017 in hypertensive subjects with multiple AK lesions necessitating a field-directed treatment. The clinical setting was a third-level university center (Dermatology Unit, Tor Vergata Hospital, Rome). The antihypertensive regimen was recorded to identify subjects under treatment with thiazides (hydrochlorothiazide, chlorothiazide, chlorthalidone, alone or in combination) diuretic drugs (or other known photosensitizing compounds) (Cohort group A), or other anti-hypertensive non-photosensitizing medicines (Cohort group B). Eligibility criteria were: men or women aged $\geq 40$ years with a history of drug-controlled essential hypertension of at least five years and the presence of at least $5 \mathrm{AK}$ lesions located on the face or the scalp necessitating fielddirected therapy. Exclusion criteria were: photoinduced or photo-aggravated skin diseases, recent ( $<2$ months) intake of non-cardiovascular photosensitizing drugs. The subjects have been followed up to 6 months with three visits (at baseline, month three, and month six). Treatment of AK lesions was performed using a cream containing PXM $0.8 \%$ and sunscreen (SPF 50+) (Actixicam ${ }^{\mathrm{TM}}$; Cantabria Labs Difa Cooper; Italy) applied twice daily on the face and the scalp. AK count and dermoscopy evaluation of a target lesion (defined at baseline visit) were performed at baseline and after three and six months. AK lesion count and dermoscopy were performed by an investigator who was unaware of the type of anti-hypertensive regimen. The results of the present observational cohort trial follow the Strengthening the Reporting of Observational Studies in Epidemiology) statement checklist. ${ }^{14}$

\section{Patients and methods}

We enrolled 119 patients older than 40 years (average of age 72 years old) with a diagnosis of AKs, treated with antihypertensive drugs, including photosensitizing (mainly TDs) and non-photosensitizing drugs. The study was approved by the Medical Ethics Committee of Tor Vergata University Hospital in July 2016; all participants signed the informed consent. They were visited at baselines, and after three and six months. We collected personal history and physical parameters, furthermore reporting the class of anti-hypertensive drugs with the dosage and the duration of intake for each patient. Features of cohorts are resumed in Table 1. During all the visits, we collected data from each patient by dermoscopic evaluation. No other dermatological disorders were referred. All patients signed written consent before starting the therapy, and the study was conducted following the ethical guidelines of the Helsinki Declaration..$^{15}$ The patient was addressed to use the medical device prescribed on the area indicated. PXM $0.8 \%$ and SPF $50+$ sunscreen cream (ACTX) was applied on the target and perilesional field of cancerization $\left(25 \mathrm{~cm}^{2}\right)$. AK was evaluated at baseline $\mathrm{T} 0$, after three months (T2), and after six months (T3). We assessed the severity of a target

Table I Subjects characteristics at baseline

\begin{tabular}{|l|l|l|l|}
\hline & $\begin{array}{l}\text { Group A } \\
(\mathbf{n = 3 9 )}\end{array}$ & $\begin{array}{l}\text { Group B } \\
(\mathbf{n = 8 0 )}\end{array}$ & $\boldsymbol{P}$-value \\
\hline Sex, men/women & $26 / 13$ & $53 / 27$ & NS \\
Age, mean (SD) & $77(8)$ & $70(8)$ & 0.005 \\
Phototype I or II, \% & 53 & 48 & NS \\
History of sunburns \% & 43 & 30 & 0.05 \\
History of skin cancer \% & 45 & 47 & NS \\
$\begin{array}{l}\text { Number of AK lesion, } \\
\text { mean (SD) }\end{array}$ & $14(I)$ & 14.4 & NS \\
$\begin{array}{l}\text { Dermoscopy severity score } \\
\text { of target lesion, mean (SD) } \\
\text { BSI score, mean (SD) }\end{array}$ & $5.8(I .2)$ & $5.8(I . I)$ & NS \\
\hline
\end{tabular}

Abbreviation: $\mathrm{BSI}$, baseline severity index; NS, not significant. 
lesion through clinical dermoscopic scale score (from 0 to 4 for each item) evaluating Erythema, Scaling, Pigmentation, and Follicular Plugs (ESPFP total score; ranging from 0 for no sign, to 20 for severe sign. An investigator, unaware of the type of antihypertensive treatment (TD or non-TD), performed both the evaluations. We also evaluated at the same visits the Baseline Severity Index (BSI). The scale used for determining BSI was as follows: $0=$ no AKS visible; $1=$ clearly visible lesions; $2=$ many visible, small, moderately thick lesions or a few large, thick, rough, scaly lesions; $3=$ many thick, hypertrophic lesions clearly visible and palpable with well-defined borders. In comparison with baseline visit at month three and six, we also evaluated the Investigator Global Improvement Indices (IGII), using the following 7-point scale: $-2=$ Significantly worse, $-1=$ Slightly worse, $0=$ No change, $1=$ Slightly improved, $2=$ Moderately improved, $3=$ Significantly improved and 4= Completely improved.

\section{Data drug collection}

We examined a cohort of 119 patients receiving treatment with TDs alone or in association with other antihypertensive drugs, assessing the correlation with the onset of the AKs and other non-melanoma skin cancers. Through selfadministrated questionnaire, we collected data regarding the type and duration of anti-hypertensive treatment, checking the presence of photosensitizing compounds. Photosensitizing drugs were considered compounds such as TDs, loop diuretics, and sodium-sparing diuretics. In this observational trial, we did not consider as "definitive" photosensitizing drug compounds such as beta-blockers, calcium channel blockers, angiotensin-converting enzyme (ACE) inhibitors and angiotensin receptor blockers.

\section{Statistical analysis}

Statistical analysis was performed using GraphPad statistical software ver 13.0 (La Jolla, CA, USA). Continuous variables were expressed as mean \pm SD. The primary endpoint of the trial was the evolution of AK mean number and the dermoscopy score from baseline and after treatment in the target lesion. The paired $t$-test and the Wilcoxon test were used for the analysis of the study outcomes. A $P$-value of $<0.05$ was considered significant.

\section{Results}

The total of the screened patient was 119; of which, 74 male and 45 female were $>40$ years old. Thirty-five patients were under treatment with TDs or other known photosensitizing diuretics (Cohort Group A) and another group with a differ- ent class of anti-hypertensive drugs (ACE inhibitors, calcium channel blockers) (Cohort group B). All subjects concluded the study period. Table 1 summarizes the main demographic and clinical characteristics of the two groups. Group A subjects were significantly older than subjects of group B (77 years vs 70), and had a positive history of sunburn in a higher percentage of subjects in comparison with group B. However, there was no statistically significant difference in the two groups in the proportion of subjects with low phototype (I or II) or positive history for non-melanoma skin cancer. At baseline, AK mean (SD) lesion number was 14.1(4) in group A and 14.6(4) in the group B. ESPFP mean (SD) score at baseline was 5.8(1.2) in both groups. After three and sixmonth treatment with PXM $0.8 \%$ and sunscreen filter 50+, a significant reduction of $\mathrm{AK}$ lesions in comparison with baseline $(P=0.001)$ was observed in both groups; however, a statistically significant greater reduction was observed in group A in comparison with group B ( $-54 \%$ vs $-32 \%$; $P=0.05$ between groups) (Figure 1). Also, the ESPFP score was reduced in a higher proportion in group $\mathrm{A}$ in comparison with group B ( $-60 \%$ vs $-37 \%$ ) vs baseline values (Figure 2 ). ACTX treatment was very well tolerated. Consistent with the absolute reduction in AK count number, we observed a significantly greater decrease of BSI ( $-66 \%$ vs $-48 \%$ ) and IGII score ( $-66 \%$ vs $50 \%)$ in group A in comparison with the group B.

\section{Discussion}

Gandini et al recently conducted a meta-analysis involving observational and experimental epidemiological studies published until February $2018^{16}$ confirming the increased risk of correlation between use of TD use and SCC. TD remain one of the principal therapeutic indication in the treatment of hypertension. ${ }^{17}$ The American Agency for Cancer Research considered TD as "possibly carcinogenic to humans" because of their marked phototoxic activity. ${ }^{18}$ A recent Italian Drug use report underlines that TD are the third most used drug class after anti-platelet drugs and vitamin D supplements. ${ }^{19} \mathrm{TD}$ are well known photosensitizing compounds: the photoionization of chlorine substituents contained in TD activated by UV irradiation generated a cation radical with keratinocyte DNA instability, oxidized radicals production, and metalloprotease activation. ${ }^{20}$ The common feature of most photoactive drugs is an aromatic chlorine substituent. ${ }^{21}$ Photo-ionization represents the intermediate process responsible for phototoxic damage UV induced in chlorine-containing drugs. ${ }^{22}$ Furosemide and hydrochlorothiazide are the most widely used diuretic agents 


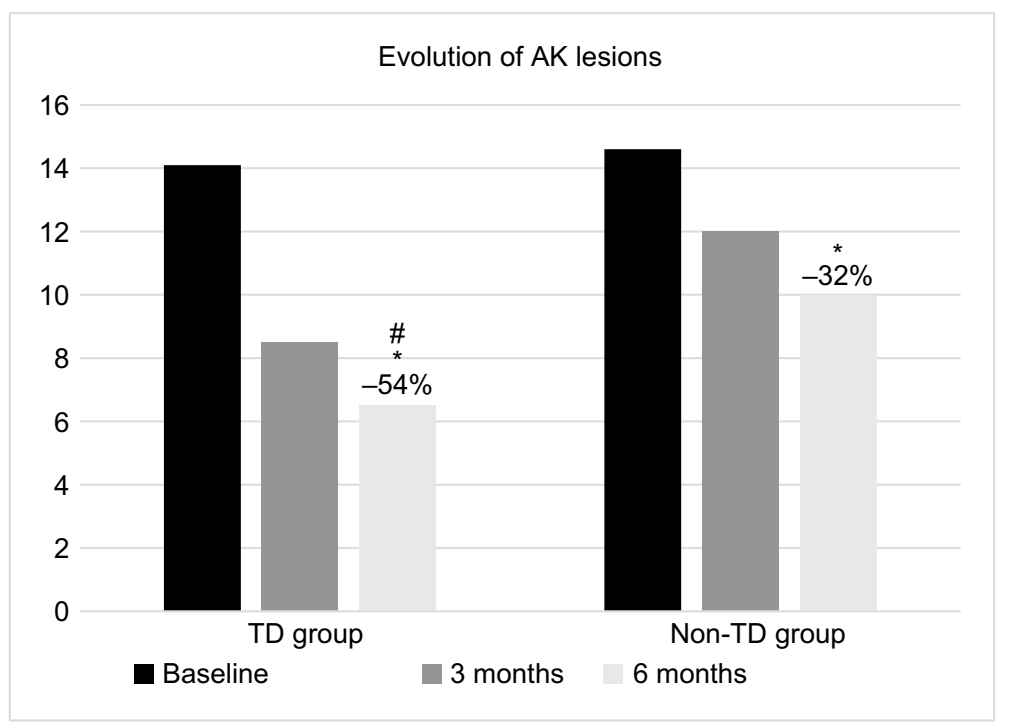

Figure I Evolution of AK lesion count in subjects under treatment with TD drugs and in subjects not under treatment with TD drugs, at baseline and after three and six months of ACTX treatment.

Notes: ${ }^{*} P<0.001$ vs baseline; ${ }^{\# P}<0.05$ vs Non-TD group.

Abbreviations: ACTX, $0.8 \%$ piroxicam and sunscreen $50+$; $A K$, actinic keratosis; TD, thiazide diuretic.

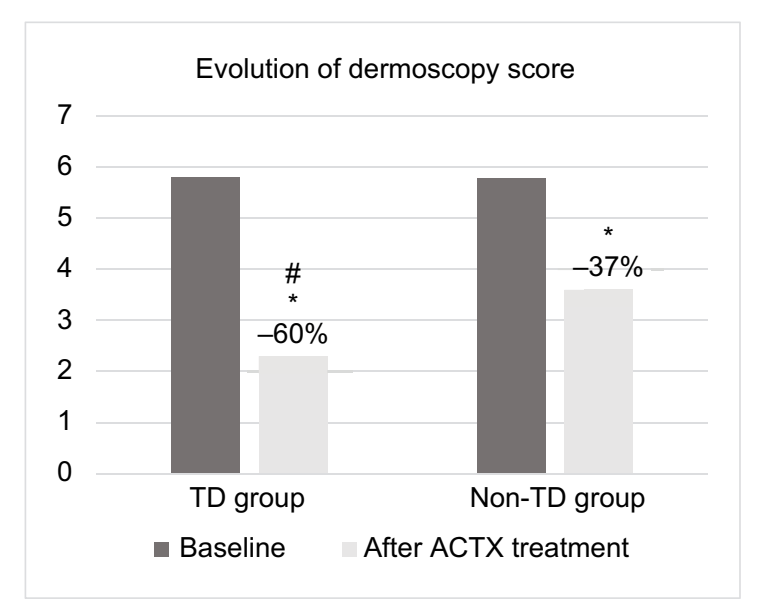

Figure 2 Evolution of dermoscopy severity ESPFP score of a target lesion in subject under treatment with TD drugs and in subjects no under treatment with TD drugs at baseline and after six months of ACTX treatment.

Notes: ${ }^{*} P<0.005$ vs baseline; ${ }^{\sharp} P<0.05$ vs Non-TD group.

Abbreviations: ACTX, $0.8 \%$ piroxicam and sunscreen 50+; ESPFP, erythema, scaling, pigmentation, and follicular plugs; TD, thiazide diuretic.

involved in photosensitivity reaction, but epidemiologic remain limited. ${ }^{23}$ In a population-based case-control study, Jensen et $\mathrm{al}^{10}$ found that the use of amiloride and hydrochlorothiazide increase the risk of SCC and melanoma, providing evidence that the use of photosensitizing agents is associated with skin cancer. These data have been confirmed in another observational study conducted in more than 5,000 subjects showing that the use of photosensitizing medication increased the risk of SCC, especially in subjects with lower phototypes. ${ }^{9}$ This observation underlines the relevance of sunscreen procedures in subjects at risk or suffering from skin cancers. ${ }^{24} \mathrm{AK}$ is considered a precursor of SCC. ${ }^{25} \mathrm{AK}$ treatment encompasses a variety of lesion-directed destruction and field-directed therapies, or a combination of both, in conjunction with additional therapies tailored to patient's needs. ${ }^{26}$ Lesion-directed therapies, such as cryotherapy, are chosen for patients with few well-defined lesions. Fielddirected therapies are recommended for any surface with multiple (more than four to eight) $\mathrm{AKs}$, for example, the face, scalp, and forearm, with the appropriateness of fielddirected therapy increasing further when the AKs occur in photo-exposed areas, and the patient has a history of significant sun exposure, recurrent AKs, history of chronic immunosuppression, and history of non-melanoma skin cancer.. ${ }^{27}$ Topical therapies are non-invasive forms of field cancerization therapy. Several topical therapies are available for the treatment of $\mathrm{AK},{ }^{28}$ including 5 -FU cream $(5 \%, 1 \%$, $0.5 \%)$, imiquimod cream ${ }^{29}(5 \%$ and $3.75 \%)$, diclofenac $3 \%$ gel, PXM $0.8 \%$ and sun filters ${ }^{30,31}$ and ingenol mebutate gel ( $5 \%$ and $3.75 \%$ ). Topical therapies in preparations, including sunscreen, are advantageous given the importance of regular sunscreen use in AKs management. ${ }^{32}$ Among the latter novel therapies, PXM, a member of the class of non-steroidal antiinflammatory drugs, is indicated for the treatment of $\mathrm{AK}$ grade I-II and field of cancerization. ${ }^{33,34}$ This topical product has been shown to be very effective in reducing AK lesions 
in a high-risk group like solid transplant organ subjects. ${ }^{35}$ Its therapeutic efficacy is probably due to the reduction of PGs and thromboxane synthesis. ${ }^{36}$ Also, PXM is able to inhibit ornithine decarboxylase (ODC) synthesis. ${ }^{37,38}$ ODC is the main enzyme responsible for the increase of cutaneous polyamines after ultraviolet irradiation and phototoxic effect by TD. ${ }^{39}$ PGs and polyamines are both involved in skin carcinogenesis. ${ }^{40,41}$ PXM belongs to the class of inhibitor of cyclooxygenase, the initial step enzyme in PG biosynthesis cascade. ${ }^{29} \mathrm{PG}$ is involved in ODC induction, with subsequent increased levels of polyamines is responsible for skin tumor development. ${ }^{42}$ Accumulating reports in the literature suggest a strong link between oncogene activation and increased polyamine biosynthesis in skin tumorigenesis. ${ }^{43} \mathrm{PXM}$ is an inhibitor of polyamines synthesis, and it has been shown to suppress skin tumor in UV-mediated damage. In this observational study in hypertensive subjects with AK, we observed that the clinical efficacy, evaluated as absolute lesion count reduction and lesion target dermoscopy evaluation after PXM and sunscreen 50+, seems to be greater in the group of subjects treated with photosensitizing diuretics in comparison with the hypertensive subjects treated with no-photosensitizing anti-hypertensive agents. These results could be attributed to a dual effect of this topical product. First, the biochemical and molecular mechanisms of action of PXM, in particular, the indirect inhibition of ODC production, could block some mechanisms underlying the specific thiazide-mediated phototoxicity. Second, this product is also an effective sunscreen $(50+$ SPF) and therefore could reduce the phototoxicity processes induced by UV exposure in subjects taking photosensitizing drugs. Some study limitations could be taken into account evaluating our results. First, this was an observational cohort trial, not an interventional controlled study. The results we obtained could be useful in planning future studies for assessing different topical treatment strategies in AK subjects with or without concomitant photosensitizing drug treatments. To improve the internal validity of our observational data, the primary end-point evaluation of our study (AK count lesion reduction) was performed by investigators unaware of the type of anti-hypertensive treatments.

\section{Conclusion}

In hypertensive subjects with multiple $\mathrm{AK}$, the topical use of ACTX (PXM 0.8\% and 50+ sunscreen) is associated with a significant reduction of lesion count and an improvement in the field of cancerization evaluated with dermoscopy. The clinical efficacy is more pronounced in subjects under photosensitizing (mainly thiazides) diuretics treatment in comparison with the hypertensive subject not under treatment with photosensitizing diuretic drugs.

\section{Acknowledgment}

This manuscript received no funding.

\section{Author contributions}

All authors contributed toward data analysis, drafting and critically revising the paper, gave final approval of the version to be published, and agree to be accountable for all aspects of the work. MM performed the assessor-blinded evaluation of coded pictures for the calculation and scoring of primary outcomes.

\section{Disclosure}

MM is an employee of Cantabria Labs Difa Cooper. The authors report no other conflicts of interest in this work.

\section{References}

1. Fargnoli MC, Altomare G, Benati E, et al. Prevalence and risk factors of actinic keratosis in patients attending Italian dermatology clinics. Eur J Dermatol. 2017;27(6):599-608.

2. Siegel JA, Korgavkar K, Weinstock MA. Current perspective on actinic keratosis: a review. Br J Dermatol. 2017;177(2):350-358.

3. Flohil SC, van der Leest RJ, Dowlatshahi EA, Hofman A, de Vries E, Nijsten T. Prevalence of actinic keratosis and its risk factors in the general population: the Rotterdam Study. J Invest Dermatol. 2013;133(8):1971-1978.

4. Salasche SJ. Epidemiology of actinic keratoses and squamous cell carcinoma. J Am Acad Dermatol. 2000;42(1):S4-S7.

5. Lebwohl M. Actinic keratosis: epidemiology and progression to squamous cell carcinoma. Br J Dermatol. 2003;149(s66):31-33.

6. Bickers DR, Athar M. Oxidative stress in the pathogenesis of skin disease. J Invest Dermatol. 2006;126(12):2565-2575.

7. Moore DE. Drug-induced cutaneous photosensitivity: incidence, mechanism, prevention and management. Drug Saf. 2002;25(5):345-372.

8. Gómez-Bernal S, Alvarez-Pérez A, Rodríguez-Pazos L, GutiérrezGonzález E, Rodríguez-Granados MT, Toribio J. Photosensitivity due to thiazides. Actas Dermosifiliogr. 2014;105(4):359-366.

9. Robinson SN, Zens MS, Perry AE, Spencer SK, Duell EJ, Karagas MR. Photosensitizing agents and the risk of non-melanoma skin cancer: a population-based case-control study. J Invest Dermatol. 2013;133(8):1950-1955.

10. Jensen AØ, Thomsen HF, Engebjerg MC, Olesen AB, Sørensen HT, Karagas MR. Use of photosensitising diuretics and risk of skin cancer: a population-based case-control study. Br J Cancer. 2008;99(9):1522-1528.

11. de Vries E, Trakatelli M, Kalabalikis, D et al. Known and potential new risk factors for skin cancer in European populations: a multicentre case-control study. Br J Dermatol. 2012;167(Suppl 2):1-13.

12. Traianou A, Ulrich M, Apalla Z, et al. EPIDERM Group. Risk factors for actinic keratosis in eight European centers: a case-control study British Journal of Dermatology. Br J Dermatol. 2012;167(Suppl 2):36-42.

13. Ruiter R. High-ceiling diuretics+ tendency to sunburn raises risk of BCC. Reactions. 2010;1313:7.

14. von Elm E, Altman DG, Egger M, Pocock SJ, Gøtzsche PC, Vandenbroucke JP; STROBE Initiative. The Strengthening the Reporting of Observational Studies in Epidemiology (STROBE) statement: guidelines for reporting observational studies. Int J Surg. 2014;12(12):1495-1499. 
15. General Assembly of the World Medical Association. World Medical Association Declaration of Helsinki: ethical principles for medical research involving human subjects. J Am Coll Dent. 2014; 81(3):14.

16. Gandini S, Palli D, Spadola G, et al. Anti-hypertensive drugs and skin cancer risk: a review of the literature and meta-analysis. Crit Rev Oncol Hematol. 2018;122:1-9.

17. James PA, Oparil S, Carter BL, et al. 2014 evidence-based guideline for the management of high blood pressure in adults: report from the panel members appointed to the Eighth Joint National Committee (JNC 8). JAMA. 2014;311(5):507-520.

18. Pedersen SA, Gaist D, Schmidt SAJ, Hölmich LR, Friis S, Pottegård A. Hydrochlorothiazide use and risk of nonmelanoma skin cancer: A nationwide case-control study from Denmark. J Am Acad Dermatol. 2018;78(4):673-681.

19. AAVVL'uso dei farmaci in Italia - Rapporto OsMed; 2016. Available from: http://www.aifa.gov.it/content/luso-dei-farmaci-italia-rapportoosmed-2016.

20. Moore DE, Tamat SR. Photosensitization by drugs: photolysis of some chlorine-containing drugs. J Pharm Pharmacol. 1980;32(3): $172-177$.

21. Moore DE. Drug-induced cutaneous photosensitivity. Drug Safety. 2002;25(5):345-372.

22. Tamat SR, Moore DE. Photolytic decomposition of hydrochlorothiazide. J Pharm Sci. 1983;72(2):180-183.

23. Quintero B, Miranda MA. Mechanisms of photosensitization induced by drugs: A general survey. Ars Pharm. 2000;41:27-46.

24. Elias J, Fernandez G. Guidance on minimizing photosensitivity/phototoxicity reactions between medication and sunlight. Sussex Partnership, NHS Foundation Trust. 2016.

25. Ackerman AB, Mones JM. Solar (actinic) keratosis is squamous cell carcinoma. Br J Dermatol. 2006;155(1):9-22.

26. Jetter N, Chandan N, Wang S, Tsoukas M. Field cancerization therapies for management of actinic keratosis: a narrative review. Am J Clin Dermatol. 2018;19(4):543-557.

27. Werner RN, Stockfleth E, Connolly SM, et al. Evidence and consensusbased (S3) Guidelines for the Treatment of Actinic Keratosis-International League of Dermatological Societies in cooperation with the European Dermatology Forum-Short version. J Eur Acad Dermatol Venereol. 2015;29(11):2069-2079.

28. Gold MH, Nestor MS. Current treatments of actinic keratosis. J Drugs Dermatol. 2006;5(2 Suppl):17-25.

29. Stockfleth E, Meyer T, Benninghoff B, Christophers E. Successful treatment of actinic keratosis with imiquimod cream 5\%: a report of six cases. Br J Dermatol. 2001;144(5):1050-1053.
30. Campione E, Diluvio L, Paternò EJ, Chimenti S. Topical treatment of actinic keratoses with piroxicam $1 \%$ gel: a preliminary open-label study utilizing a new clinical score. Am J Clin Dermatol. 2010;11(1):45-50.

31. Puviani M, Galloni C, Marchetti S, et al. Efficacy of a film-forming medical device containing sunscreen (50+) and piroxicam $0.8 \%$ in actinic keratosis and field cancerization: a multicenter, assessor-blinded, 3 month trial. Curr Med Res Opin. 2017;33(7):1255-1259.

32. de Berker D, Mcgregor JM, Hughes BR. British Association of Dermatologists Therapy Guidelines and Audit Subcommittee. Guidelines for the management of actinic keratoses. $\mathrm{Br} J$ Dermatol. 2007;156(2):222-230.

33. Campione E, Paternò EJ, Candi E, et al. The relevance of piroxicam for the prevention and treatment of nonmelanoma skin cancer and its precursors. Drug Des Devel Ther. 2015;9:5843-5850.

34. Babino G, Diluvio L, Bianchi L, et al. Long-term use of a new topical formulation containing piroxicam $0.8 \%$ and sunscreen: efficacy and tolerability on actinic keratosis. A proof of concept study. Curr Med Res Opin. 2016;32(8):1345-1349.

35. Garofalo V, Ventura A, Mazzilli S, et al. Treatment of multiple actinic keratosis and field of cancerization with topical piroxicam $0.8 \%$ and sunscreen $50+$ in organ transplant recipients: a series of 10 cases. Case Rep Dermatol. 2017;9(3):211-216.

36. Brogden RN, Heel RC, Speight TM, Avery GS. Piroxicam: a review of its pharmacological properties and therapeutic efficacy. Drugs. 1981;22(3):165-187.

37. Reddy BS, Nayini J, Tokumo K, Rigotty J, Zang E, Kelloff G. Chemoprevention of colon carcinogenesis by concurrent administration of piroxicam, a nonsteroidal antiinflammatory drug with D,L-alphadifluoromethylornithine, an ornithine decarboxylase inhibitor, in diet. Cancer Res. 1990;50(9):2562-2568.

38. Carbone PP. Phase I chemoprevention study of piroxicam and alfa difluoromethylornithine Cancer epidemiology. Cancer Epidemiol Biomarkers Prev. 1998;7:907-912.

39. Alexiou GA, Lianos GD, Ragos V, Galani V, Kyritsis AP. Difluoromethylornithine in cancer: new advances. Future Oncol. 2017;13(9):809-819.

40. Gerner EW, Meyskens FL. Polyamines and cancer: old molecules, new understanding. Nat Rev Cancer. 2004;4(10):781-792.

41. Furstenberger G, Marks F. Prostaglandins, epidermal hyperplasia, and skin tumor promotion. In: Arachidonic Acid Metabolism and Tumor Promotion. Boston: Springer; 1985:49-72.

42. Gilmour SK. Polyamines and nonmelanoma skin cancer. Toxicol Appl Pharmacol. 2007;224(3):249-256.

43. Einspahr JG, Bowden GT, Alberts DS. Skin cancer chemoprevention: strategies to save our skin. In: Tumor Prevention and Genetics. Berlin, Heidelberg: Springer; 2003:151-164.
Clinical, Cosmetic and Investigational Dermatology

\section{Publish your work in this journal}

Clinical, Cosmetic and Investigational Dermatology is an international, peer-reviewed, open access, online journal that focuses on the latest clinical and experimental research in all aspects of skin disease and cosmetic interventions. This journal is included on PubMed. The manuscript management system is completely online

\section{Dovepress}

and includes a very quick and fair peer-review system, which is all easy to use. Visit http://www.dovepress.com/testimonials.php to read real quotes from published authors 